\title{
Early-warning Model of Support Vector Machine Based on Hybrid Quantum-behaved Particle Swarm Optimization for Power System Operational Status
}

\author{
Jinchao Li ${ }^{\mathrm{a}}$, Fangwei Duan ${ }^{\mathrm{b}, \text { * }}$ \\ School of Economics and Management, North China Electric Power University, Beijing, China \\ aemail: lijc78@163.com, bemail:dfw8906@163.com, "corresponding author
}

Keywords: Electric power system, Operation state, Evaluation indexes, Support vector machine (SVM), Quantum particle swarm

\begin{abstract}
In order to overcome the problem that the support vector machine (SVM) is not timely in the early warning of the electric power system operation status and the prediction precision is not high, the improved quantum particle swarm optimization algorithm is combined with the SVM to establish a model of hybrid quantum particle swarm optimization SVM for the electric power system operation state early warning, and carry on the simulation for evaluation indexes. The simulation results show that the model is feasible and effective.
\end{abstract}

\section{Introduction}

Electric power industry is the basic industry and public utility of the national economy. The safe and reliable operation of electric power system bears on the overall situation of national economic development and social stability. Nowadays, the scale of power grid is expanding and the complexity is also significantly increasing. It has entered a new stage of large capacity, large unit, high parameter, ultrahigh voltage and long distance transmission. However, the situation of the safe and stable operation of power grid should not be blindly optimistic, domestic and overseas in recent years, the number of emergencies caused serious influence on safe operation of power grid. Therefore, the research of analysis, identification and early-warning of the electric power system operation status is of high urgency and significance.

In 1967, Dyliacco divided and defined five operating states of the electric power system: normal operation state, alert state, emergency state, system collapse and restore state [1]. For the various states of electric power system operation and security evaluation, some literatures propose that the safety evaluation and early-warning system has evolved from the traditional energy management system (EMS), such as the literature [2] proposes grid real-time security early-warning system that based on the traditional EMS, and the literature [3] on the basis of the literature [2] the security early-warning and decision support system of control center is designed from the three dimensions of time, space and control target. In the study of risk assessment, the literature [4] proposes the risk index evaluation system, based on the principle of risk assessment, the security and stability of electric power system can be effectively assessed, but fail to show the relationship between risk of the electric power system and the changes of operating state. The literature [5-7] use the algorithm of the literature [4] to evaluate the security and stability of the electric power system operation. The literature [8-10] apply the credibility theory in the field of mathematics to the operation risk assessment of the electric power system and has attained stage achievement.

\section{Early-warning Indexes of Electric Power System Operation Status}

According to the characteristics of production, transmission and use of electric energy which are instantaneity, balance, uncertainty and complexity, this paper constructs an evaluation system of 
electric power system operation state with 14 third-level indexes from the four perspectives of real-time balance, prevention and control, the degree of accident and support system, as shown in Figure 1.

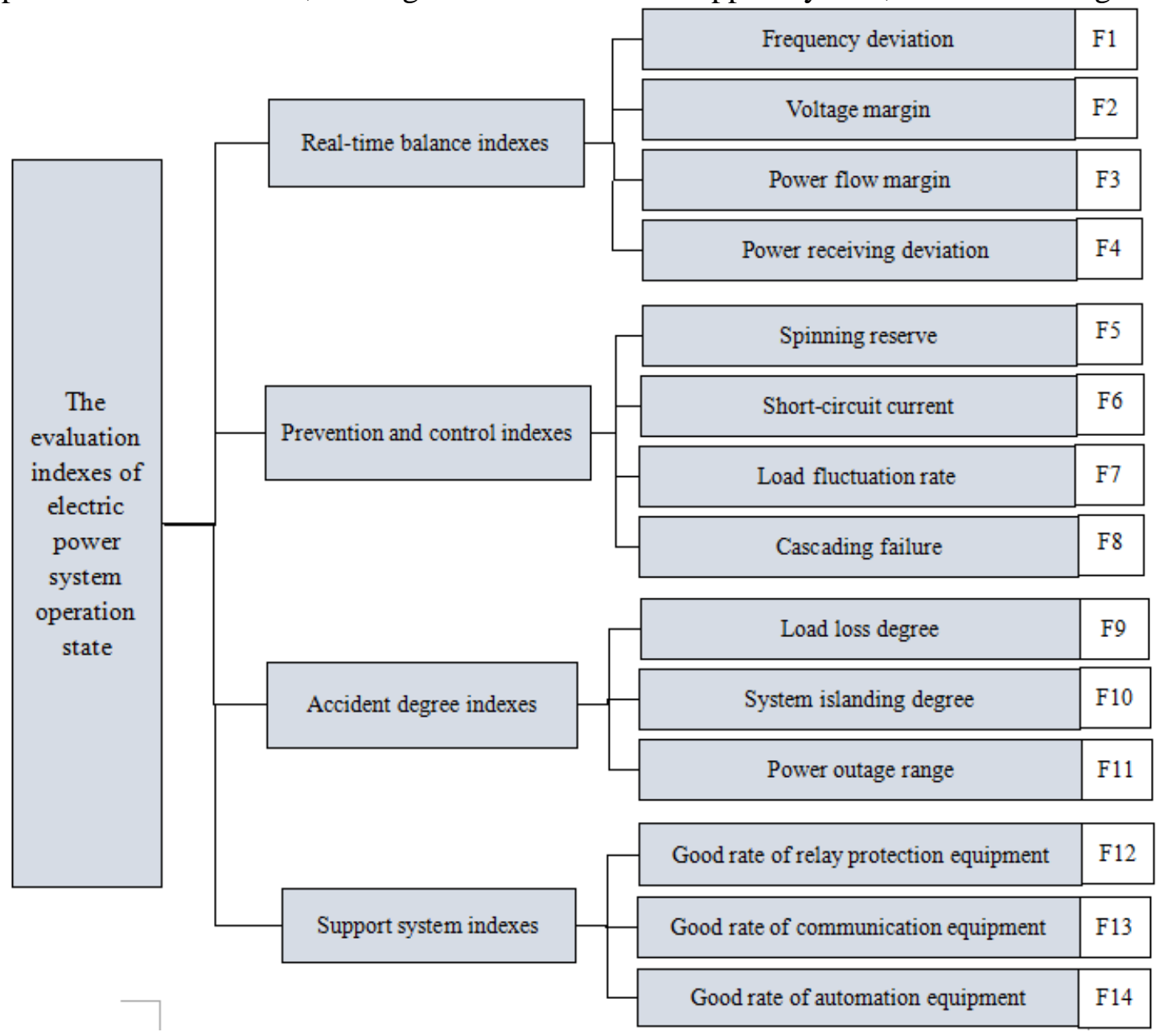

Fig. 1. The evaluation indexes of electric power system operation state

\section{The Early-warning Model}

Attribute Reduction Technology. Rough-Set Theory is put forward by Polish mathematician Z. Pawlak in the early 80s. The evaluation procedures of Rough-Set are discretizing the index data, screening the index, calculating the index weight and the evaluating comprehensive value in sequence. Attribute reduction of index

This paper uses the algorithm based on discernibility matrix and logical operation, and propose a rough-set model, which does not need to construct decision attributes.

Support Vector Machine (SVM). Based on statistical learning theory, the robust regression theory and dual programming theory, Vapnik et al. Of Bell Labs proposed a learning algorithm called support vector machine (SVM).

Quantum-behaved Particle Swarm Optimization (QPSO). In 2004, Quantum-behaved Particle Swarm Optimization (QPSO) was proposed by Sun et al. [11,12]. The algorithm is that the particle has the motion law of the quantum, without specific trajectory, but would gather around an attractive potential, so that the aggregation of the group can be maintained. The advantages of this algorithm is to ensure that the particle swarm flew over the whole solution space, and ensure the better global optimization capability. In quantum space, the particles search in the whole feasible solution space. This is a new particle swarm optimization which can guarantee the global convergence. Therefore the 
global searching performance of QPSO algorithm is much better than the standard PSO algorithm.

The particles of QPSO algorithm has only the position information and no velocity information, and the control parameters of the algorithm are relatively few. Compared with the PSO, the QPSO algorithm has the advantages of good global searching capability, good robustness and short computation time.

Flow Chart of Electric Power System Operation Early-warning Model. In this paper, a hybrid quantum-behaved particle swarm optimization (SVSO) support vector machine (SVM) power system operation state early warning model is established based on attribute reduction technique. The detailed flow chart is shown in Fig.2.

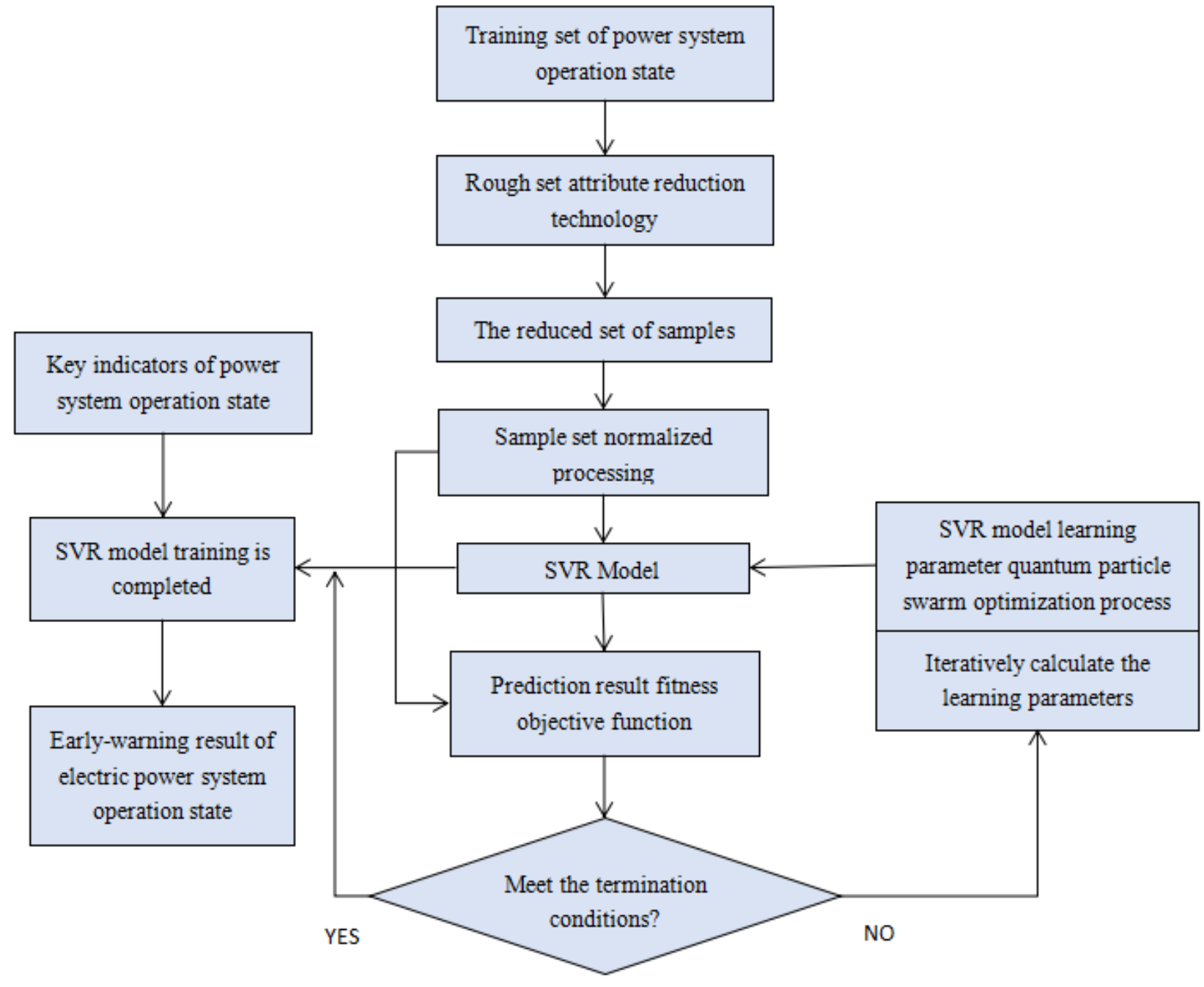

Fig.2 Flow chart of electric power system operation early-warning model

\section{Simulation Results of Early-warning Model of Electric Power System Operation State}

Show some examples of simulation data for power system operation in Table 1, and it is convenient for getting the key factors affecting the operation state of electric power system.

Using rough set reduction technology to get the key factors affecting the operation state of electric power system: $\{$ F1, F2, F3, F7, F8, F9, F11, F12\}.

After the early-warning test of electric power system operation, the results are shown as Fig.3. And the quantum particle swarm optimization algorithm is set as Table 2. 
Table1 Examples of simulation data for power system operation

\begin{tabular}{|c|c|c|c|c|c|c|c|c|c|c|c|c|c|c|c|}
\hline Index & F1 & F2 & F3 & F4 & F5 & F6 & F7 & F8 & F9 & F10 & F11 & F12 & F13 & F14 & State \\
\hline 1 & $\begin{array}{c}0.12 \\
8 \%\end{array}$ & $\begin{array}{c}49.28 \\
3 \%\end{array}$ & $\begin{array}{c}49.87 \\
3 \%\end{array}$ & $\begin{array}{c}-1.00 \\
\%\end{array}$ & $\begin{array}{c}5.00 \\
\%\end{array}$ & 8 & $\begin{array}{l}11 \\
\%\end{array}$ & $\begin{array}{c}18.00 \\
\%\end{array}$ & $\begin{array}{c}0.94 \\
\%\end{array}$ & $\begin{array}{c}44.47 \\
\%\end{array}$ & $\begin{array}{c}14.34 \\
\%\end{array}$ & $\begin{array}{l}85 \\
\%\end{array}$ & $\begin{array}{l}97 \\
\%\end{array}$ & $\begin{array}{l}93 \\
\%\end{array}$ & 2 \\
\hline 2 & $\begin{array}{c}0.89 \\
7 \%\end{array}$ & $\begin{array}{c}49.74 \\
6 \%\end{array}$ & $\begin{array}{c}49.00 \\
4 \%\end{array}$ & $\begin{array}{c}-5.00 \\
\%\end{array}$ & $\begin{array}{c}6.00 \\
\%\end{array}$ & 15 & $8 \%$ & $\begin{array}{c}10.00 \\
\%\end{array}$ & $\begin{array}{c}41.48 \\
\%\end{array}$ & $\begin{array}{c}17.73 \\
\%\end{array}$ & $\begin{array}{c}13.00 \\
\%\end{array}$ & $\begin{array}{l}93 \\
\%\end{array}$ & $\begin{array}{l}86 \\
\%\end{array}$ & $\begin{array}{l}89 \\
\%\end{array}$ & 3 \\
\hline 3 & $\begin{array}{c}0.46 \\
5 \%\end{array}$ & $\begin{array}{c}49.89 \\
2 \%\end{array}$ & $\begin{array}{c}49.65 \\
7 \%\end{array}$ & $\begin{array}{c}-6.00 \\
\%\end{array}$ & $\begin{array}{c}6.00 \\
\%\end{array}$ & 14 & $5 \%$ & $\begin{array}{c}29.00 \\
\%\end{array}$ & $\begin{array}{c}10.74 \\
\%\end{array}$ & $\begin{array}{c}21.34 \\
\%\end{array}$ & $\begin{array}{c}3.35 \\
\%\end{array}$ & $\begin{array}{l}84 \\
\%\end{array}$ & $\begin{array}{l}98 \\
\%\end{array}$ & $\begin{array}{l}99 \\
\%\end{array}$ & 1 \\
\hline 4 & $\begin{array}{c}0.09 \\
4 \%\end{array}$ & $\begin{array}{c}49.27 \\
1 \%\end{array}$ & $\begin{array}{c}49.05 \\
8 \%\end{array}$ & $\begin{array}{c}-6.00 \\
\%\end{array}$ & $\begin{array}{c}10.00 \\
\%\end{array}$ & 11 & $5 \%$ & $\begin{array}{c}5.00 \\
\%\end{array}$ & $\begin{array}{c}15.33 \\
\%\end{array}$ & $\begin{array}{c}10.08 \\
\%\end{array}$ & $\begin{array}{c}16.30 \\
\%\end{array}$ & $\begin{array}{l}99 \\
\%\end{array}$ & $\begin{array}{l}95 \\
\%\end{array}$ & $\begin{array}{l}99 \\
\%\end{array}$ & 1 \\
\hline 5 & $\begin{array}{c}0.83 \\
7 \%\end{array}$ & $\begin{array}{c}49.71 \\
0 \%\end{array}$ & $\begin{array}{c}49.55 \\
5 \%\end{array}$ & $\begin{array}{c}3.00 \\
\%\end{array}$ & $\begin{array}{c}6.00 \\
\%\end{array}$ & 9 & $5 \%$ & $\begin{array}{c}30.00 \\
\%\end{array}$ & $\begin{array}{c}35.94 \\
\%\end{array}$ & $\begin{array}{c}40.85 \\
\%\end{array}$ & $\begin{array}{c}15.42 \\
\%\end{array}$ & $\begin{array}{l}92 \\
\%\end{array}$ & $\begin{array}{l}83 \\
\%\end{array}$ & $\begin{array}{l}83 \\
\%\end{array}$ & 3 \\
\hline
\end{tabular}

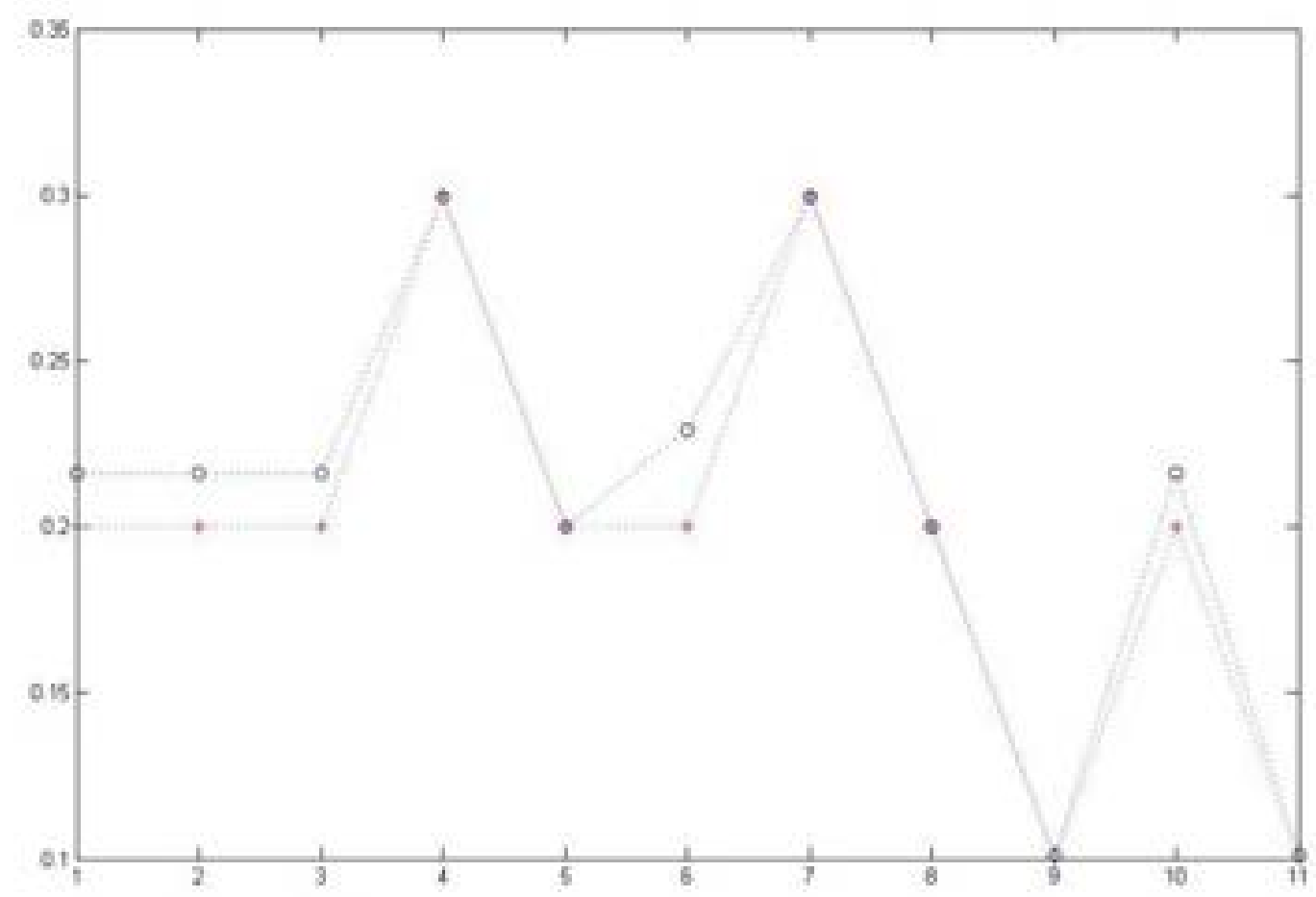

The '+' represents the real value, the 'o' represents the forecasting value.

Fig. 3 Early warning test results of power system operation

Table 2 The optimal learning parameter of quantum particle swarm

\begin{tabular}{cc}
\hline Parameter & QPSO \\
\hline $\mathrm{C}$ & 7.5847 \\
$\varepsilon$ & 0.1876 \\
$\sigma$ & 0.2153 \\
\hline
\end{tabular}

\section{Conclusion}

In this paper, a multidimensional factors set of electric power system operation state including text information is constructed. Then the factors set is reduced by using rough set attribute reduction technology, which reduce the input index of SVM and improve the learning and training speed of SVM. The quantum particle swarm optimization algorithm is used to optimize solution of the SVM learning 
parameters, and the forecasting accuracy of the SVM is improved. Finally, the intelligent forecasting model of the electric power system operation state is completed.

\section{References}

[1] Ding M., Li S.H., Wu H.B., et al., Analysis of Power System Operation State Based on Adequacy and Security. Proceedings of The Chinese Society for Electrical Engineering, 2004. 24(4) 43-49.

[2] Sun H.B., Hu J.Y., Liu Y.H., et al., Evolution of power dispatch control center: real-time power security early warning system. Automation of Electric Power System, 2004. 28(15) 1-6.

[3] Zhang B.M., Wu S.N., Cai B., et al., Design of an early warning and security countermeasure system for electric power control centers. Automation of EIectric Power Systems, 2006. 30(6) 1-5.

[4] Ming N., MCCALLEY J.D., VITTAL V., et al., Online risk-based security assessment. IEEE Trans on Power Systems, 2003. 18(1) 258-256.

[5] Lu B., Tang G.Q., Application of risk-based security assessment in power system. Automation of EIectric Power Systems, 2000. 25(11) 61-64.

[6] Chen W.H., Jiang Q.Y., Cao Y.J., et al., Risk-based vulnerability assessment in complex power system. Power System Technology, 2005. 29(4) 12-17.

[7] Chen W.H., Jiang Q.Y., Cao Y.J., et al., Risk assessment of voltage collapse in power system. Power System Technology, 2005. 29(19) 6-11.

[8] Feng Y.Q., Zhang B.M., Wu W.C., et al, Power system operation risk assessment based on credibillty theory: Part one propound and development of operation risk assessment. Automation of Electric Power Systems, 2006. 30(1) 17-23.

[9] Feng Y.Q., Zhang B.M., Wu W.C., et al., Power system operation risk assessment based on credibillty theory: Part two theory fundament. Automation of Electric Power Systems, 2006. 30(2) 11-21.

[10] Feng Y.Q., Zhang B.M., Wu W.C., et al., Power system operation risk assessment based on credibillty theory: Part three engineering application. Automation of Electric Power Systems, 2006. 30(3) 11-16.

[11] Li L., Niu B., Particle Swarm Optimization Algorithm, Beijing: Metallurgy Industry Press, 2009.

[12] Sun D.I., Ashley B., Brewer B., et al., Optimal Power Flow By Newton Approach. IEEE Transactions on Power Apparatus and Systems, 1984. PAS-103(10) 2864-2880. 